\title{
WINTER PREY COLLECTION AT A PERENNIAL COLONY \\ OF PARAVESPULA VULGARIS (L.) \\ (HYMENOPTERA: VESPIDAE)
}

\author{
By Parker Gambino \\ Department of Entomological Sciences \\ University of California \\ Berkeley, California, U.S.A. 94720
}

\section{INTRODUCTION}

Diet is a fundamental aspect of an organism's biology. In eusocial vespid wasps the food intake of a mature colony, including nutrition of immatures, is determined by the foraging behavior of workers. Yellowjackets of the genus Paravespula Blüthgen meet the protein requirements of the colony by capturing live arthropods and collecting flesh from dead animals. By enabling these species to utilize a broader resource base, scavenging likely contributed to the evolution in this genus of a colony cycle characterized by higher worker populations and greater longevity than in Vespula Thompson, a closely related genus in which only live prey is taken (MacDonald et al., 1976).

Prey collection by freely foraging Paravespula colonies has been described in detail by Kleinhout (1958), Kemper and Dohring (1962), Broekhuizen and Hordijk (1968), and Archer (1977). Numerous shorter lists of prey are available, (cf. Spradbery (1973) for a literature review). Broekhuizen and Hordijk (1968) investigated the response of $P$. vulgaris (L.) to artificial manipulations of prey densities in trees, while MacDonald et al. (1974) offered various prey items in screen-enclosed foraging areas. Heinrich (1984) gave a good account of general foraging behavior of individual workers and Free (1970) investigated handling of honeybee prey by workers.

Paravespula species undergo an annual monogynous cycle over most of their range, but in mild-weathered areas, perennial polygynous colonies sometimes develop (Spradbery, 1973). These colonies, characterized by enormous populations of workers, occur especially

*Revised manuscript received by the editor July 7, 1986. 
in areas recently invaded by Paravespula. Although perennation and polygyny represent significant deviations from the typical Paravespula pattern, the sporadic appearance of such colonies has hindered study. Published prey studies have addressed only annual colonies, thus the discovery of a perennial Paravespula colony at the University of California provided an opportunity to study its winter diet.

\section{Materials AND Methods}

I first noticed the colony of Paravespula vulgaris (L.) on October 10, 1984. Typical annual colonies of this native species initiated in April or May usually begin to decline in the fall. The high level of activity (about 300 worker sorties per minute) indicated that this colony had been functional since at least spring 1984, and suggested that it might persist for another year. In fact, the colony remained vigorous through a second summer, with a final observation of external worker activity on February 6, 1986.

The colony was located about $25 \mathrm{~m}$ north of Callaghan Hall ticket kiosk on the Berkeley campus of the University of California, at elevation $75 \mathrm{~m}$. The immediate surrounding area is a mixed stand of Monterey pine (Pinus radiata D. Don) and coast live oak (Quercus agrifolia Neé) over a grass ground cover dominated by Ehrharta erecta Lam. Strawberry Creek, flowing basically east to west, passes within 40 meters.

The subterranean nest was under a fallen log about 1 meter in diameter, which supported a lush growth of ivy (Hedera helix L.). Active entrance holes were at ground level on both sides of the log. The log was well shaded, although the west entrance received some direct afternoon sun.

To facilitate sampling, I constructed devices to restrict yellowjacket access to the nest at each entrance. To sample from the east entrance, I sealed it and netted the returning foragers as they hovered near it. After separating prey from the workers by shaking the net, I either allowed workers to fly from the net or anaesthetized them with carbon dioxide and removed them. A typical 40 minute net-sampling session involved approximately 40 sweeps of the net.

Beginning April 5, 1985, I used a modified funnel trap to collect from the west entrance. This passive method was more efficient at collecting foragers returning with prey. The trap was left in place 
approximately 15 minutes per sampling session. Captured workers were anaesthetized and shaken from the trap. Anaesthetized workers were returned to the vicinity of the nest entrance for which they had been bound. Items separated from the workers were immediately transferred to $70 \% \mathrm{EtOH}$.

I identified sorted samples to lowest feasible taxonomic levels with the assistance of workers at the Essig Museum, University of California, Berkeley. An item which was recognizable as a single prey load was counted even if it was only a fragment of an organism. For example, a honeybee abdomen counted as one record of Apis mellifera $\mathrm{L}$.

I visited the colony to observe wasp behavior daily from January 5 to May 10, 1985, and sampled approximately weekly. Time of day and environmental conditions during sampling varied somewhat, but most sessions were during the early to mid afternoon of bright sunny days.

\section{RESULTS}

I analyzed a total of 1306 items, many of which were only fragments and/or badly mauled. Precision of identification was variable . Thus, while some relatively intact prey items could be identified to species, other more macerated fragments of arthropods could not be identified below phylum. Because there is no way to know which items were captured live (predation sens. str.) and which were scavenged, I classified all food items as prey. No items of food made or prepared by humans were identified.

The 914 prey items that could be identified at least to order are summarized in Table 1 according to taxa and collection dates. ${ }^{1}$ Temporal variation of selected prey items in the colony's diet, illustrated in Figure 1, reflects the sequential availability of potential prey species, based on their life history patterns.

I began the study during the flight period of the sawfly, Xyela radiatae Burdick, when adults were so abundant that they actually crawled into my net during several collection sessions. Accordingly, $X$. radiatae was the dominant prey item in January ( $79 \%$ of determined specimens). Yellowjackets commonly hunted in the short

\footnotetext{
'A more detailed list of prey is available from the author on request.
} 


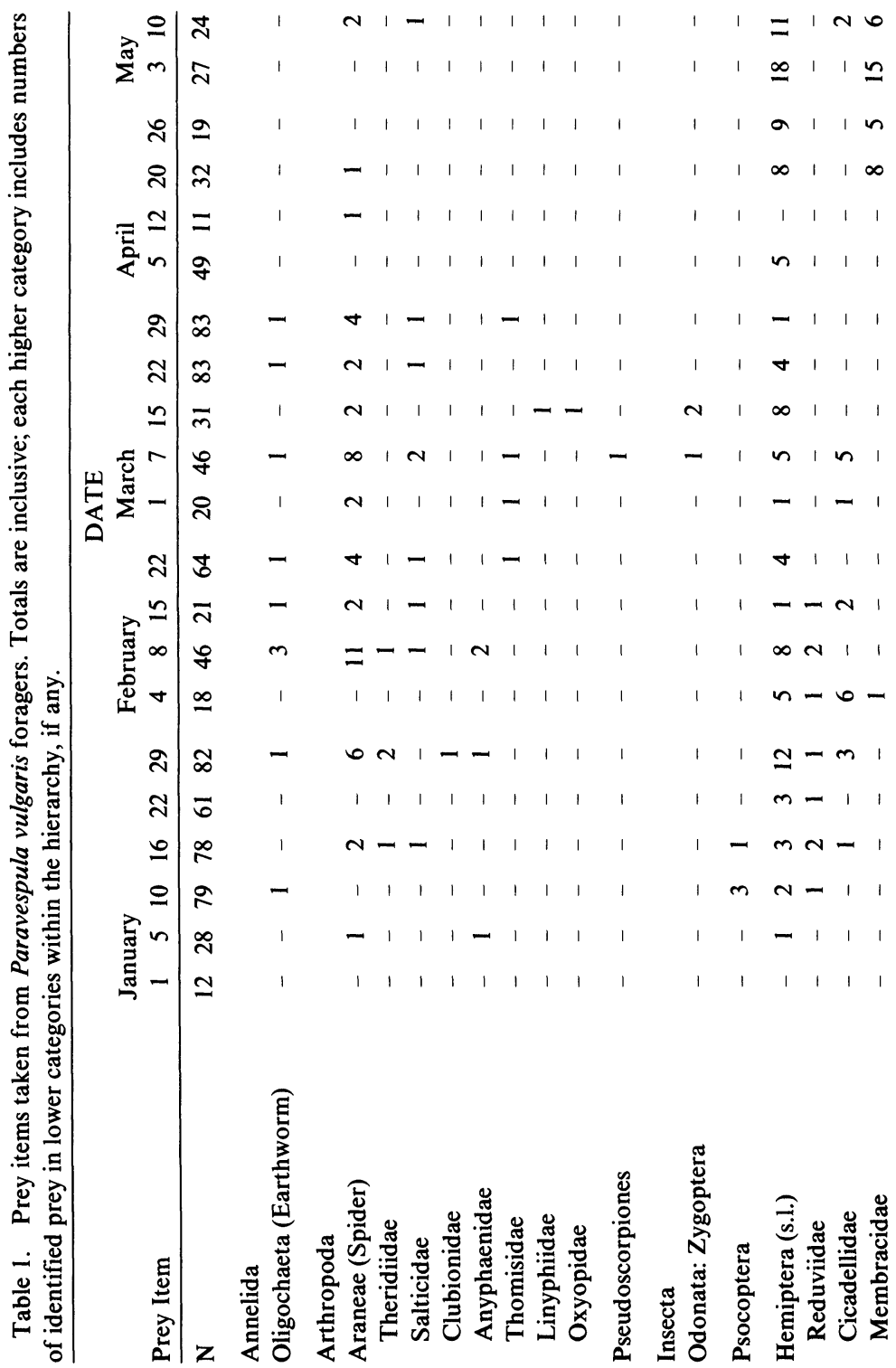




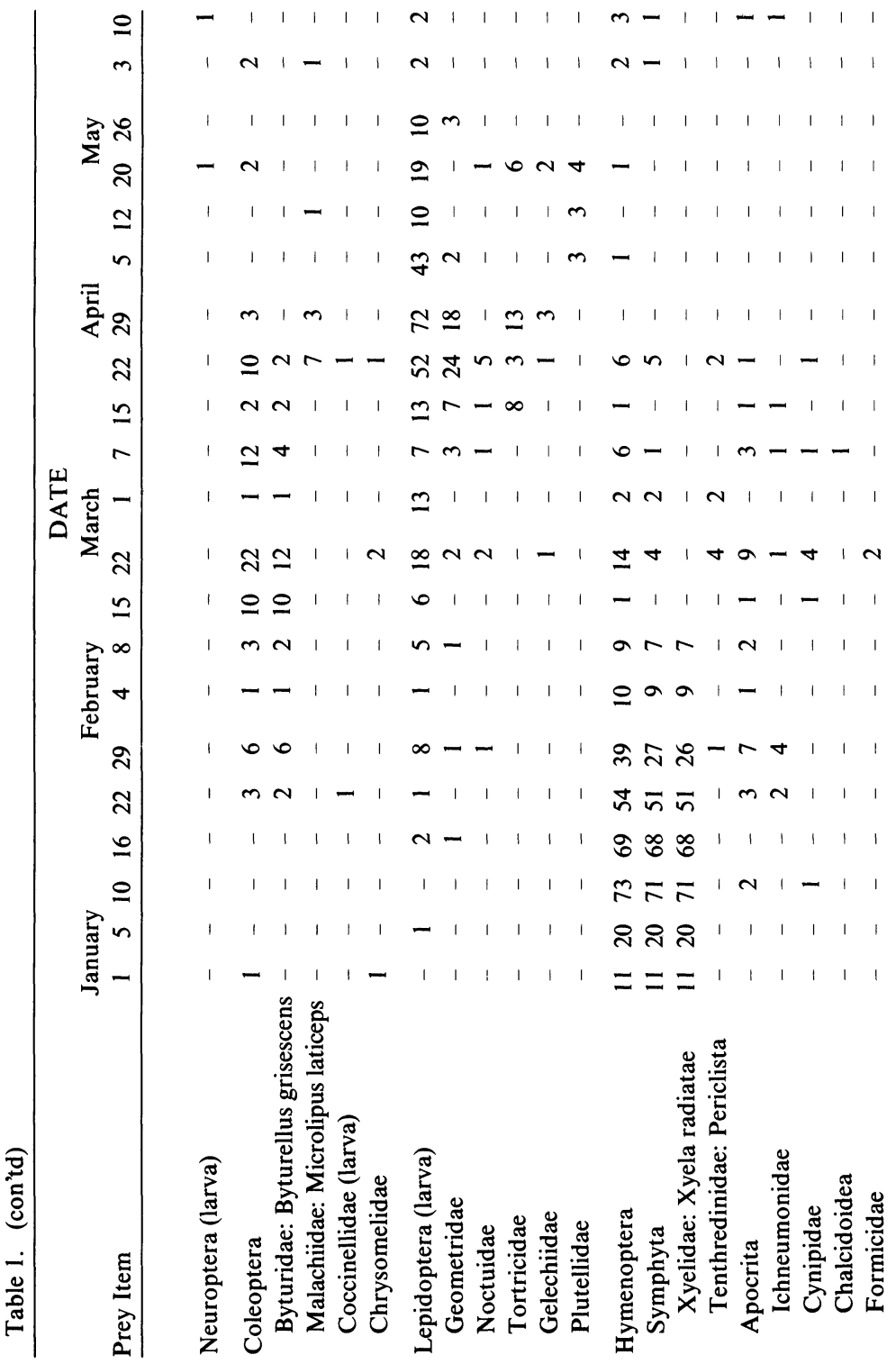




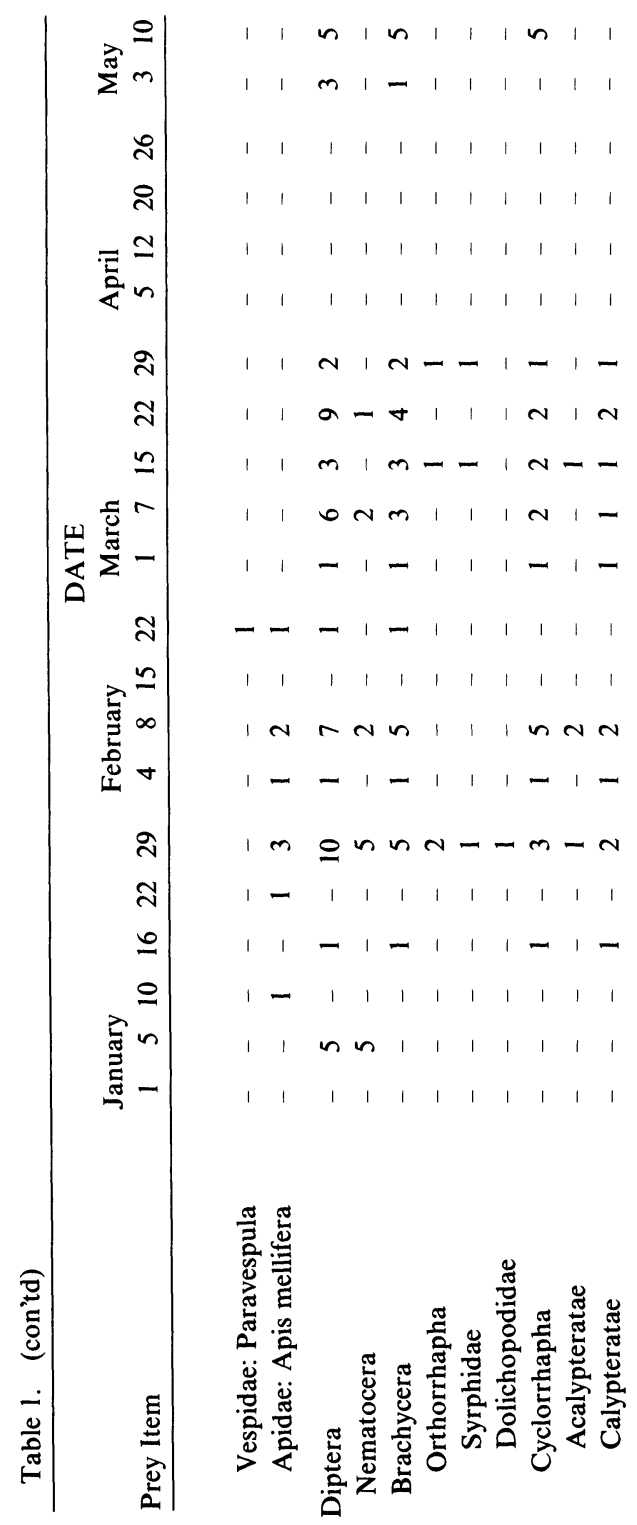


grass near the colony, especially beneath Pinus radiata, the xyelid's host plant (Burdick, 1961). Workers flying close to the ground thoroughly scanned plant surfaces, paying special attention to areas of contrasting colors and textures to locate and capture surfaceinhabiting arthropods, which comprised the vast majority of the colony's prey. I observed attempted and successful captures of $X$. radiatae adults on grass blades. These sawflies, presumably newly emerged from underground pupae, seemed especially vulnerable to Paravespula predation.

In late February, the beetle, Byturellus grisescens (Jayne), reached its greatest abundance in the prey samples. Although I was unable to capture any of these beetles myself, they oviposit on oak catkins (J. Doyen, pers. comm.). This was the first good suggestion of the importance of oak insects in the diet of the colony. Of the many tree species occurring on the University campus, Q. agrifolia, a native, is one of the most common.

As the season progressed, hunting at ground level became less frequent, and foragers shifted their attention to tree foliage, particularly $Q$. agrifolia. Local population explosions of caterpillars (Lepidoptera) in late March and April, and the treehopper, Cyrtolobus vanduzeei Goding, in May were also tracked by this colony (Fig. 1). Again, most of the identifiable Lepidoptera and Membracidae were of taxa known to be associated with $Q$. agrifolia.

\section{Discussion}

The wide taxonomic array of arthropod prey and focus on abundant prey species shown by the observation colony are consistent with known habits of the genus Paravespula. Scavenging, a characteristic of the genus, is suspected in the collection of pieces of earthworm and Apis mellifera, as well as some other items which were tangled in silk strands and may have been taken from spider webs. Collection of proteinaceous food prepared for human consumption, a habit accounting for the pest status of $P$. vulgaris in many areas (MacDonald et al., 1976) was not detected. Although such food was certainly within the flight range of foraging workers, it was not common in the immediate vicinity of the colony, and foragers may have become conditioned to locate arthropod prey. In general, the data from the observation colony indicate that the flesh 


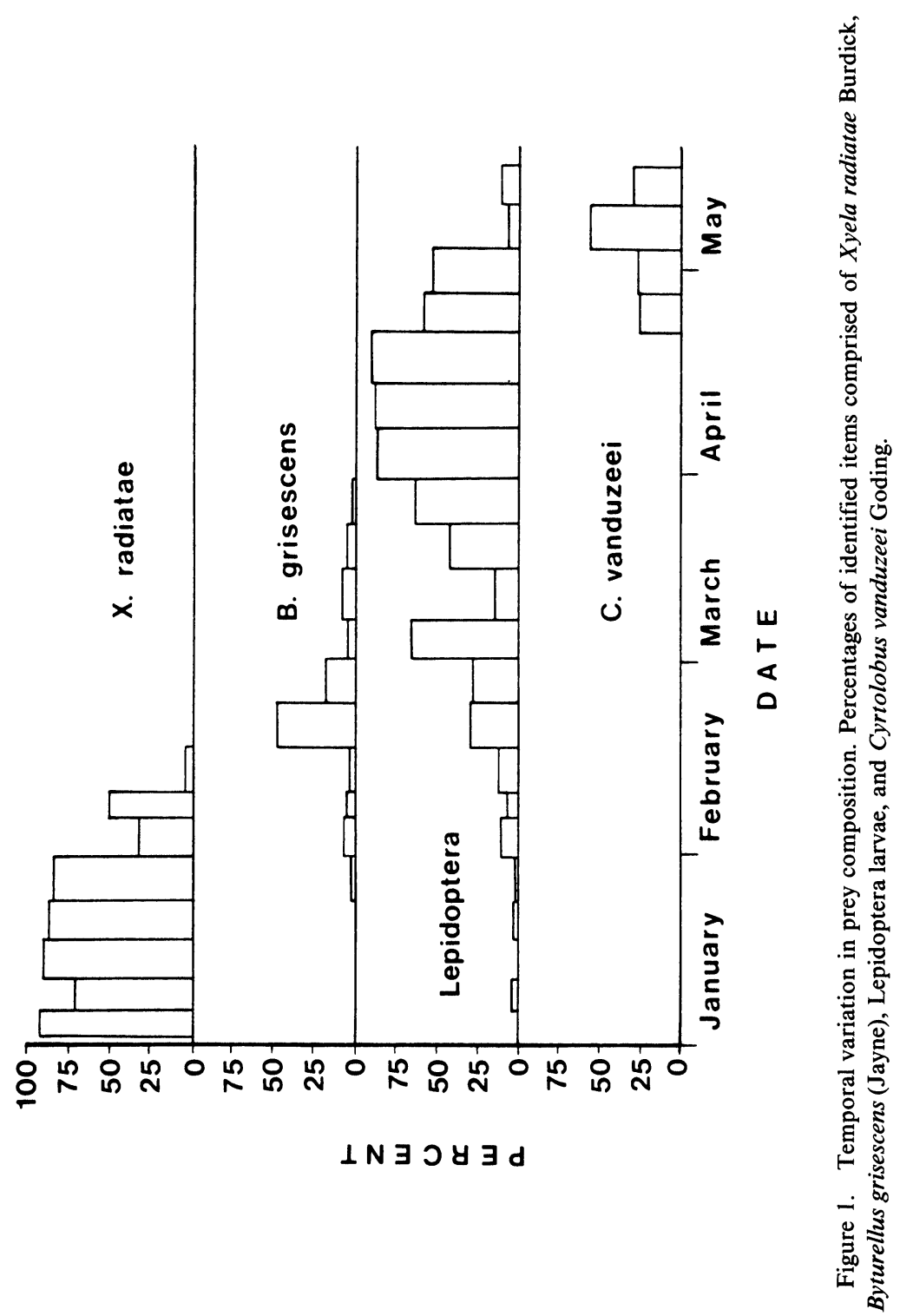


collection behavior of perennial colonies probably does not differ substantially from that of annual colonies.

\section{SUMMARY}

This study suggests that in coastal California natural food resources are sufficient to sustain healthy overwintering Paravespula colonies. The $P$. vulgaris colony under study took a wide assortment of prey, and adjusted its diet according to local abundances of prey species. $Q$. agrifolia, a native tree common in the vicinity of the colony, was the source of many of the insects comprising its diet.

\section{ACKNOWLEDGMENTS}

The success of this study resulted from the contributions of many co-workers in the Department of Entomological Sciences, University of California, Berkeley. Vernard Lewis discovered the colony, and Tina Sterret provided technical assistance. Howell Daly, John Doyen, Jerry Powell, Evert Schlinger, Stuart McKamey, Woodrow Middlekauff, and Jim Whitfield assisted in identifying prey. Howell Daly, John De Benedictis and Woodrow Middlekauff reviewed the manuscript and offered suggestions for its improvement. Financial support was furnished in part by the Northern California chapter of the ARCS Foundation.

\section{Literature Cited}

ArCher, M. E.

1977. The weights of forager loads of Paravespula vulgaris (Linn.) (Hymenoptera: Vespidae) and the relationship of load weight to forager size. Ins. Soc. 24(1): 95-102.

Broekhuizen, V. S., AND C. HordiJK

1968. Untersuchungen über die Beute von Paravespula vulgaris L. (Hym., Vespidae) und ihre Abhängigkeit von der Beutetierdichte. Z. Ang. Entomol. 62: 68-77.

Burdick, D. J.

1961. A taxonomic and biological study of the genus Xyela Dalman in North America. Univ. Calif. Publ. Entomol. 17(3): 285-356.

FREE, J. B.

1970. The behavior of wasps (Vespula germanica L. and V. vulgaris L.) when foraging. Ins. Soc. 17(1): 11-20. 
HEINRICH, B.

1984. Strategies of thermoregulation and foraging in two vespid wasps, Dolichovespula maculata and Vespula vulgaris. J. Comp. Physiol. B 154: 175-180.

Kemper, V. H., AND E. DOHRING

1962. Untersuchungen über die Ernährung sozialer Faltenwespen Deutschlands, inbesondere von P. germanica und P. vulgaris. Z. Ang. Zoologie 49(2): 227-280.

Kleinhout, J.

1958. Het verzmelen van prooien van sociale wespen. De Levende Natuur 61: 179-182.

MacDonald, J. F., R. D. AKre, And W. B. Hill

1974. Comparative biology and behavior of Vespula atropilosa and V. pensylvanica (Hymenoptera: Vespidae). Melanderia 18: 1-65.

MacDonald, J. F., R. D. AKre, and R. W. Matthews.

1976. Evaluation of yellowjacket abatement in the United States. Bull. Entomol. Soc. Amer. 22(4): 397-401.

SPRADBERY, J. P.

1973. Wasps. University of Washington Press, Seattle. xvi +408 pp. 

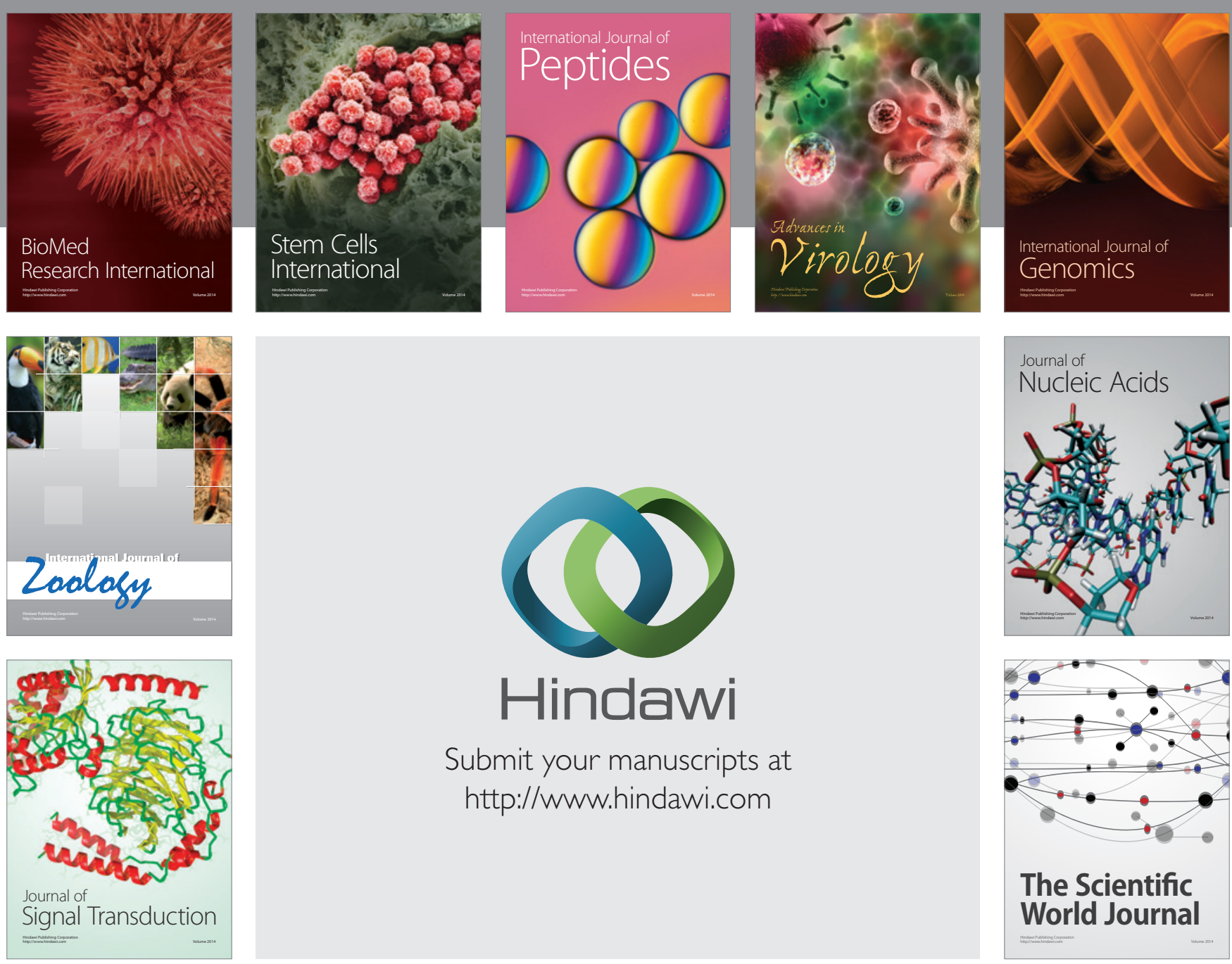

Submit your manuscripts at

http://www.hindawi.com
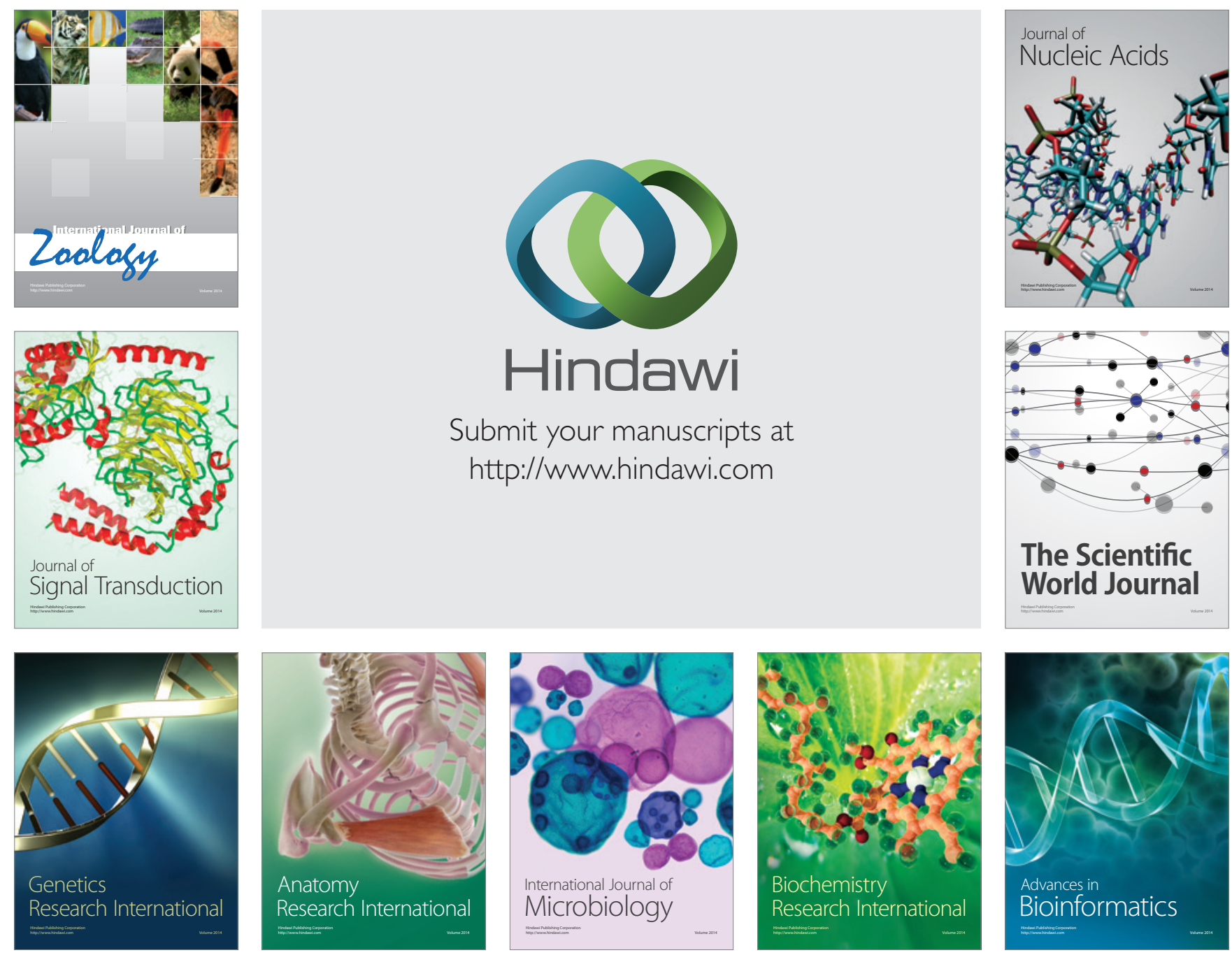

The Scientific World Journal
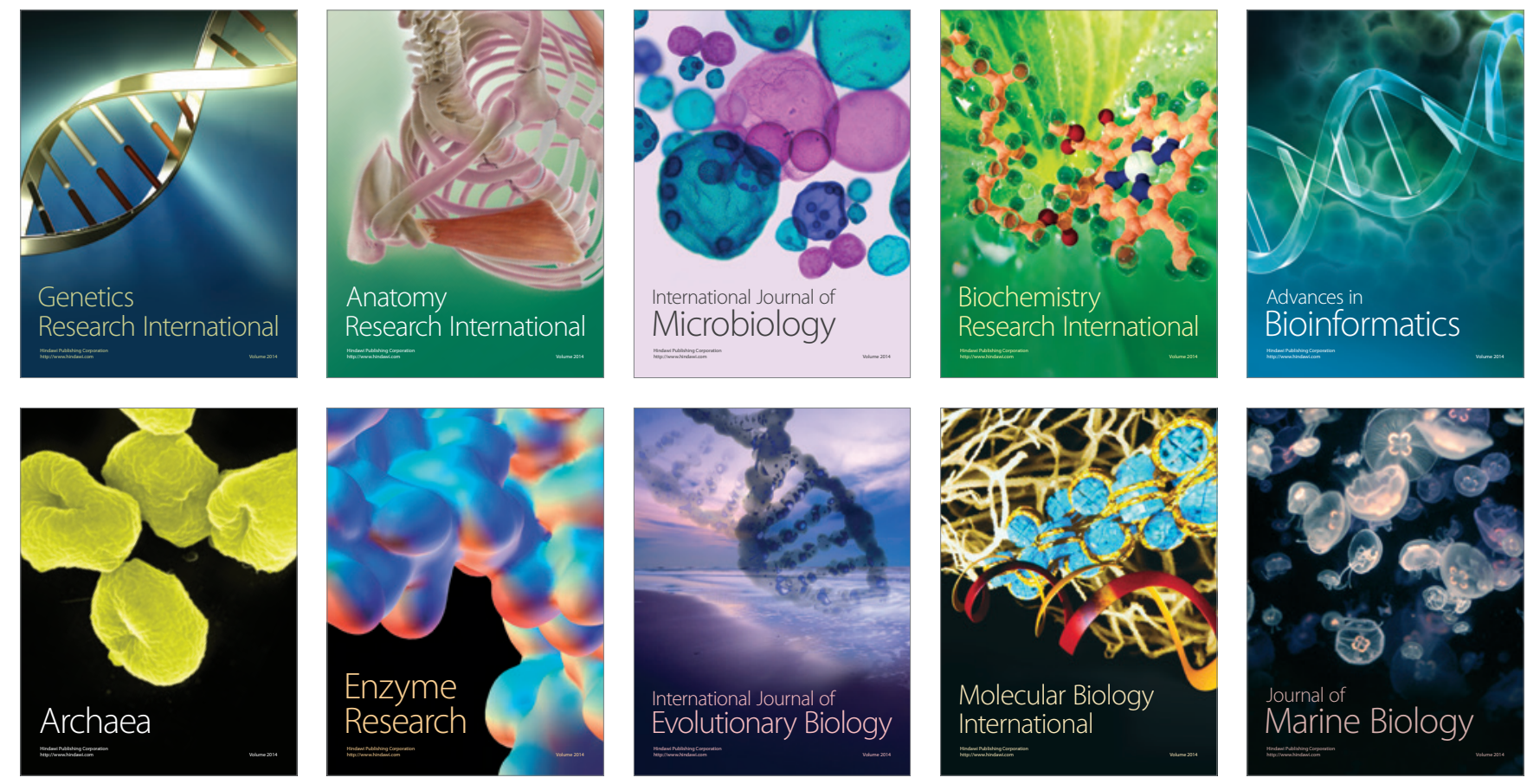